Eleventh EuroBlight workshop

Hamar (Norway), 2008

\title{
Regional spore dispersal as a factor in disease risk warnings for potato late blight: a proof of concept
}

\author{
G.J.T. KESSEL'1, P. SKELSEY², A.A.M. HOLTSLAG ${ }^{3}$, A.F. MOENE³, W. VAN DER WERF ${ }^{2}$ \\ ${ }^{1}$ Wageningen University and Research Centre, Plant Research International, \\ P.O. Box 16, 6700 AA Wageningen, The Netherlands \\ ${ }^{2}$ Wageningen University and Research Centre, Plant Sciences, Crop and Weed Ecology Group, \\ P.O. Box 430, 6700 AK Wageningen, The Netherlands \\ ${ }^{3}$ Wageningen University and Research Centre, Environmental Sciences, Meteorology and Air Quality \\ Group, P.O. Box 47, 6700 AA Wageningen, The Netherlands
}

\section{SUMMARY}

This study develops and tests novel approaches that significantly reduce the fungicide input necessary for potato late blight control while maintaining the required high level of disease control. The central premise is that fungicide inputs can be reduced by reducing dose rates on more resistant cultivars, by omitting applications on days when conditions are unsuitable for atmospheric transport of viable sporangia and by adapting the dose rate to the length of the predicted critical period.

These concepts were implemented and tested in field experiments in 2007 and 2008 in the North Eastern potato growing region in the Netherlands which is known for its high potato late blight disease pressure. Field experiments contained three starch potato cultivars, representing a range in resistance to potato late blight from susceptible to highly resistant, and a series of decision rules determining spray timing and incorporating an increasing number of variables such as: remaining fungicide protection level, critical weather, atmospheric capacity for viable transport of sporangia and the length of the predicted critical period.

The level of cultivar resistance was used to reduce the dose rate of the preventive fungicide Shirlan (a.i. fluazinam) by default.

A $50 \%-75 \%$ reduction of the fungicide input proved possible in both years without adverse consequences to the crop or yield. The principles can be used in many decision contexts, but further work is needed to test and refine the methods before it can be used in practice.

\section{KEY WORDS}

Phytophthora infestans, spores, dispersal, decision support, disease control, environmental impact.

\section{INTRODUCTION}

Potato late blight is an ongoing problem in the global potato industry (Hijmans et al., 2000), demanding grower attention from day-to-day, and still causing losses despite this attention. It is estimated that $P$. infestans is responsible for multi-billion dollar losses annually in global tomato and potato production (Duncan, 1999; Birch and Whisson, 2001; Haverkort et al., 2008). Chemical control is still the most important measure used, and many growers anticipate that disease control requires regular applications of fungicides at high rates and short intervals throughout the growing season. This situation is being questioned, in part due to an increase in environmental awareness

PPO-Special Report no. 13 (2009), 91 - 96 
and public concern about the negative side effects of fungicide use in agriculture, and in part due to concerns regarding the development of pathogen resistance to chemical products. Efforts to reduce the environmental impact of potato cultivation are now driving exploration into new options to reduce the number of sprays, and/or the dosage, while ensuring crop health.

\section{MATERIALS AND METHODS}

Models and submodels are described in Skelsey et al., (2009). Field experiments were conducted in 2007 and 2008 in Valthermond, the Netherlands in the centre of the Dutch northeastern starch potato growing area. A randomized, split-plot design was used, with three potato cultivars, two (2007) or five (2008) late blight management systems, and four replications. Potato cultivars were used as main plots and potato late blight management systems as sub-plots. Each sub-plot measured $6 \mathrm{~m} \times 12 \mathrm{~m}$. Potato cultivars were Festien (resistant), Seresta (moderately resistant), and Karakter (2007) or Aveka (2008) (susceptible); all starch potato cultivars. Two Curzate treatments were applied on the first two critical periods of the growing season to eliminate latent tuber infections. From then onwards, spray decisions were based on historical and predicted weather and the recommendations of the decision support rules relevant to each specific treatment (Table 1). For a spray advice to be issued all relevant criteria had to be fulfilled. By default, the resistant cultivar was sprayed with $25 \%$, the moderately resistant cultivar with $50 \%$ and the susceptible cultivar with $100 \%$ of the recommended Shirlan dose rate of $0.41 /$ ha. Spray treatments were applied maximally one day before the actual start of the critical period.

SIMCAST's (Grunwald et al., 2000, 2002) fungicide units (FU's) were used to determine the remaining level of fungicide protection. Blightdays as described by Skelsey et al., (2009) were used to determine critical days, days with sufficiently long periods of leaf wetness to support infection. The spatial add on determines the daily, cultivar specific, distance weighted infection pressure (DWIP) as described by Skelsey et al (2009) and compares it to a threshold value (the 33 or 50\% percentile of a list of DWIP values covering 30 years of relevant critical days). Finally, the length of the predicted critical period is calculated by applying the Blightdays criteria to the seven day weather forecast. When a critical period was predicted, the Shirlan dose rate was reduced proportionally to the length of the predicted critical period with seven days of consecutive critical weather requiring the 'full', cultivar specific, reduced Shirlan dose rate given above.

Table 1. Components of the individual decision support systems as applied in the field experiment of 2007 and 2008. All criteria included in a system have to be fulfilled for spray advice to be issued.

\begin{tabular}{|c|c|c|c|c|c|}
\hline \multirow[t]{2}{*}{ Year } & \multirow[t]{2}{*}{ System } & \multicolumn{4}{|c|}{ Spray criteria included } \\
\hline & & $\begin{array}{c}\text { Remaining fungicide } \\
\text { protection }\end{array}$ & $\begin{array}{l}\text { Critical } \\
\text { weather }\end{array}$ & $\begin{array}{c}\text { Spatial } \\
\text { criterium } \\
(33 \text { or } 50 \%)\end{array}$ & $\begin{array}{l}\text { Length predicted } \\
\text { critical period }\end{array}$ \\
\hline \multirow[t]{2}{*}{2007} & $\mathrm{FU}_{2007}$ & $+^{1}$ & -2 & - & - \\
\hline & Spatial33 3007 & + & - & + & - \\
\hline \multirow[t]{5}{*}{2008} & $\mathrm{FU}_{2008}$ & + & - & - & - \\
\hline & $\mathrm{CP}_{2008}$ & + & + & - & - \\
\hline & Spatial33 2008 & + & + & + & - \\
\hline & Spatial $50_{2008}$ & + & + & + & - \\
\hline & LengthCP ${ }_{2008}$ & + & + & + & + \\
\hline
\end{tabular}

: All criteria incorporated in a system have to be fulfilled for spray advice to be issued

${ }^{1}$ : Criterium is included in the system.

${ }^{2}$ : Criterium is not included in the system. 
The summer of 2007 was warm and wet. According to KNMI (the Royal Dutch Meteorological Society; http://www.knmi.nl/), this period saw the second wettest July on record since 1901. In contrast, the summer of 2008 started out relatively dry and was average for the rest of the time.

Disease severity was assessed once or twice per week using the PD scale (de Visser and Meier, 2000). Following completion of the cropping cycle, the plots were desiccated with Reglone.

\section{RESULTS}

\section{Field experiment 2007}

Over the course of the field experiment, $\mathrm{FU}_{2007}$ recommended a total of 14 fungicide applications. The supplementary spatial component incorporated in Spatial33 $33_{2007}$ modified a total of three of the 14 spray recommendations for the resistant cultivar Festien. On these occasions, cultivars Karakter and Seresta were sprayed whereas cultivar Festien was left untreated. The negated spray recommendation was kept in memory and if in the following days the risk of viable spore transport was high (according to the supplementary spatial component) then fungicides were applied to the untreated plots. This was the case on the day following the first modified spray recommendation, and fungicides were accordingly applied to the untreated Festien plots. On the second and third occasions where a spray decision was modified, conditions continued to be unsuitable for transport of viable spores over distance (according to the supplementary spatial component) and as a result, both chemical treatments were avoided altogether. A high level of disease control was achieved by both DSSs despite (very) favorable conditions for potato late blight and high disease pressure from the direct surroundings of the experiment during large parts of the growing season. Reducing the fungicide dose rates according to resistance level of the cultivar proved to be an effective strategy as there was no significant difference in final disease levels between cultivars. Similarly, the difference in the level of disease control afforded by the two DSSs were not significant. This serves to demonstrate that the supplementary spatial component for DSSs can reduce the number of sprays recommended in a growing season and maintain adequate levels of crop protection.

\section{Field experiment 2008}

The 2008 experiment was designed to give more insight in the individual contribution of a range of "spray triggering events" to the overall performance of the control strategy and the fungicide input (Table 1).

The control strategy based on fungicide degradation alone $\left(\mathrm{FU}_{2007} \& \mathrm{FU}{ }_{2008}\right)$ resulted in a solid control of potato late blight on all cultivars with 16 sprays (Table 2). Including fungicide degradation and critical weather resulted in 8 - 9 spray recommendations. The level of blight control of $\mathrm{CP}_{2008}$ was equal to $\mathrm{FU}_{2007 / 2008}$ but required 7-8 spray applications less. Adding the criteria on influx of viable sporangia ( $33 \%$ criterion) reduced the fungicide input by 1 application on the resistant cultivar. Results for the theoretical number of applications are given here because the eradicant treatments became necessary due to an insufficiently strict definition for blightdays. The $50 \%$ criterion for influx of viable sporangia resulted in only 3 spray applications on the resistant cultivar Festien (including 2 eradicant applications) but $P$. infestans severity got out of hand indicating this profile incorporates too much risk on the resistant cultivar. On the moderately resistant and susceptible cultivar the number of sprays and the performance of Spatial $50_{2008}$ was identical to CP2008. When the length of the predicted critical period was taken into account to reduce the recommended Shirlan dose rate, this did not affect the number of sprays or performance but the fungicide input in $\mathrm{kg} / \mathrm{ha}$ was significantly reduced, especially on the moderately resistant and susceptible cultivar (Table 2). 
Table 2. Fungicide input in 2008 for the systems included in the experiment and expressed as the number of sprays applied or the number of full dose rate equivalents $(0.41$ Shirlan/ha) applied.

Number of spray applications

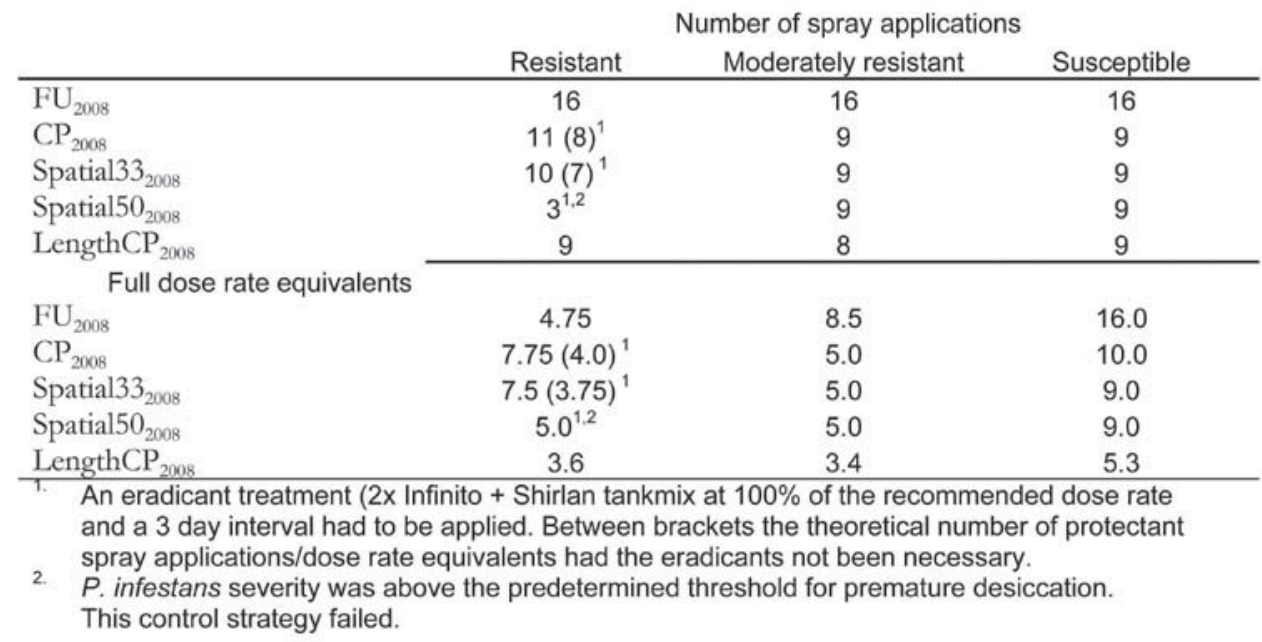

\section{CONCLUSIONS}

Fundamentally, this study is concerned with including more meteorological information in operational decision support. Spatial epidemiology has been scarcely used in operational decision support. Adaptation of the dose rate to the length of the predicted critical period has never been considered for practical reasons. However, when the chemical input and its effects on the environment are questioned, both concepts may play an important role in reducing the environmental burden of potato late blight control.

Development of spatial risk factors for regional spore dispersal from aerobiological models offers a new approach for manipulation of spray intervals in such systems. Previously, the influx component of the infection risk was largely ignored because it is difficult to handle. Instead it was assumed that spore influx always takes place at significant levels so that decisions come to depend on local conditions only. One of the strengths of the approach outlined here lies in the comprehensive use of forecast data already incorporated in many DSSs A further advantage is the applicability of this concept to a range of similar pathosystems characterized by aerial dispersal of inoculum. It has been demonstrated here that spatial risk algorithms are easily incorporated into existing frameworks in the form of a supplementary spatial component, with model results conveniently expressed in the form of a yes-or-no spray modification decision. Results from the field trials showed that in the periods of normal disease pressure approximately $1 / 3$ of the fungicide applications can be saved for the most resistant of the three cultivars tested, which was otherwise sprayed with only $25 \%$ of the recommended dose rate of Shirlan. The total reduction of fungicide input for the resistant cultivar (Festien) was high at almost $80 \%$. A high level of protection was maintained in all systems throughout both seasons, except in plots treated according to the $\mathrm{Spatial}_{50} \mathrm{O}_{2008}$ system which used an influx threshold which was simply too high. Overall, the results demonstrates that the supplementary spatial component can provide robust control whilst saving approximately $1 / 3$ of the number of sprays.

With respect to the systems that reduce the Shirlan dose rate proportionally to the length of the predicted critical period proved to result in reliable potato late blight control with an additional 
significant reduction of the fungicide input, especially on the moderately resistant and susceptible cultivar. In contrast, the influx criteria resulted in savings on the fungicide input especially in the resistant cultivars.

Further field trials are required before definitive conclusions can be drawn as to the utility of the approaches outlined in this paper. Both approaches however are not limited to potato late blight and the methods developed here could also prove to be useful in a decision context for other pathosystems.

\section{REFERENCES}

Birch, P.R.J., Whisson, S.C., 2001. Phytophthora infestans enters the genomics era. Mol. Plant Pathol. 2, 257-263.

de Visser, C.L.M., Meier, R., 2000. Field evaluation of four decision support systems for potato late blight in the Netherlands. In: Schepers, H. (Ed.), Proceedings of the Workshop on the European Network for Development of an Integrated Control Strategy of Potato Late Blight, Oostende, Belgium. PAV Special Report no. 6, pp. 137-155.

Duncan, J.M., 1999. Phytophthora-an abiding threat to our crops. Microbiol. Today 26, 114-116.

Grunwald, N.J., Rubio-Covarrubias, O.A., Fry, W.E., 2000. Potato late-blight management in the Toluca Valley: forecasts and resistant cultivars. Plant Dis. 84, 410-416.

Grunwald, N.J., Cadena-Hinojosa, M.A., Rubio-Covarrubias, O., Rivera-Pena, A., Niederhauser, J.S., Fry, W.E., 2002. Potato cultivars from the Mexican national potato program: sources and durability of resistance against late blight. Phytopathology 92, 688-693.

Haverkort, A.J., Boonekamp, P.M., Hutten, R., Jacobsen, E., Lotz, L.A.P., Kessel, G.J.T., Visser, R.G.F., van der Vossen, E.A.G., 2008. Societal costs of late blight in potato and prospects of durable resistance through cisgenic modification. Pot. Res. 51, 47-57.

Hijmans, R.J., Forbes, G.A., Walker, T.S., 2000. Estimating the global severity of potato late blight with GIS-linked disease forecast models. Plant Pathol. 49, 697-705.

Skelsey, P., Kessel, G.J.T., Rossing, W.A.H., van der Werf, W., in press. Parameterization and validation of a spatio-temporal model of the late blight pathosystem. Phytopathology.

Skelsey, P., Holtslag, A.A.M., van der Werf, W., 2008. Development and validation of a quasiGaussian plume model for the transport of botanical spores. Agr. Forest Meteorol. 148, $1383-1394$.

P. Skelsey, G.J.T. Kessel, A.A.M. Holtslag, A.F. Moene and W. van der Werf, 2009. Regional spore dispersal as a factor in disease risk warnings for potato late blight: A proof of concept. Agricultural and forest meteorology, 149 (2009) $419-430$. 